\title{
Pembuatan Virgin Coconut Oil (VCO) Dengan Metode Enzimatis Dan
}

\section{Fermentasi}

\section{Teja Dwi Sutanto $1^{1^{*}}$, Devi Ratnawati ${ }^{1}$, Agus Martono HP'}

1 Jurusan Kimia FMIPA Universitas Bengkulu

\section{ARTICLE INFO}

\section{Riwayat Artikel:}

Draft diterima: 09 November 2021

Revisi diterima: 01 Desember 2021

Diterima: 13 Desember 2021

Tersedia Online: 27 Desember 2021

Corresponding author:

*tejads@unib.ac.id

Citation: Sutanto, T. D., Ratnawat. D., Martono, A. H. P. 2021. Pembuatan Virgin Coconut Oil (VCO) Dengan Metode Enzimatis dan Fermentasi. ICOMES: Indonesian Journal of Community Empowerment and Service. 1(1), pp: 6-9

\begin{abstract}
ABSTRAK
Virgin coconut oil (VCO) merupakan minyak kelapa yang mempunyai kandungan asam lemak rantai sedang atau medium chain fatty acids (MCFA) yang mudah diurai oleh tubuh dengan jumlah yang sangat tinggi. Disamping itu VCO juga mempunyai kandungan antioksidan seperti tokoferol dan betakaroten yang sangat tinggi. Kegiatan PPM ini bertujuan untuk memberikan Pelatihan Pembuatan VCO dengan Metode Enzimatis dengan ekstrak buah nanas dan fermentasi dengan ragi roti pada masyarakat RT 12 RW 03 Kelurahan Pematang Gubernur, Kecamatan Muara Bangkahulu, Kota Bengkulu. Kegiatan dimulai dengan ceramah yang dilanjutkan dengan diskusi dan praktek pembuatan VCO dengan metode enzimatis dan fermentasi. Hasil pengamatan di lapangan menunjukkan bahwa masyarakat sasaran kegiatan PPM ini sangat antusias untuk mengikuti kegiatan ini karena merasa mendapatkan tambahan pengetahuan baru mengenai cara pembuatan $V C O$ yang dapat melengkapi pengetahuan mengenai teknik pembuatan $V C O$ yang sudah dikenal yaitu dengan metode pemancingan. Dengan pengetahuan pembuatan VCO yang diajarkan pada kegiatan ini maka masyarakat sasaran akan dapat mempunyai alternatif metode untuk pembuatan $V C O$ selain yang selama ini sudah dikenal dengan peralatan yang mudah diperoleh.
\end{abstract}

Kata kunci: VCO; MCFA; antivirus; enzimatis; Fermentasi

\begin{abstract}
Virgin coconut oil (VCO) is coconut oil that contains medium chain fatty acids (MCFA) which are easily broken down by the body in very high amounts. Besides that, VCO also has very high antioxidant content such as tocopherol and beta-carotene. This PPM activity aims to provide VCO Making Training with the Enzymatic Method with pineapple fruit extract and fermentation with baker's yeast in the community of RT 12 RW 03 Pematang Governor Village, Muara Bangkahulu District, Bengkulu City. The activity began with a lecture followed by a discussion and practice of making VCO with enzymatic and fermentation methods. The results of observations in the field indicate that the target community of this PPM activity is very enthusiastic to take part in this activity because they feel they have gained additional new knowledge about how to make VCO which can complement their knowledge of the known VCO making technique, namely the fishing method. With the knowledge of making VCO taught in this activity, the target community will be able to have alternative methods for making VCO other than what has been known so far with easily obtained equipment.
\end{abstract}

Keywords: VCO; MCFA; antivirus; enzymatic; Fermentation

\section{PENDAHULUAN}

Perkembangan teknologi dan preferensi konsumen yang telah mengakomodasi isu lingkungan dan kesehatan telah mendorong industry kelapa berkembang makin beragam dan mendalam. Industri yang paling jauh berkembang saat ini adalah pengolahan minyak kelapa menjadi senyawa oleokimia $(O C)$ dan turunannya yang popular dengan sebutan industri oleokimia. Senyawa oleokimia dasar yang dihasilkan dari pengolahan minyak kelapa terdiri atas asam lemak, asam lemak ester, asam lemak beralkohol dan asam lemak amina (Setiaji, 2013; Hedge, 2016; Prior dkk, 1981).

Salah satu produk hulu kelapa yang cukup terkenal pada beberapa tahun terakhir adalah virgin coconut oil (VCO). VCO merupakan merupakan salah satu produk unggulan kelapa karena manfaatnya yang sangat baik bagi kesehatan. 
Ada berbagai cara yang dapat digunakan untuk membuat $V C O$ yang secara garis besar dapat dibagi menjadi dua yaitu cara pemanasan dan cara tanpa pemanasan atau metode dingin. Dari kedua cara tersebut, metode tanpa pemanasan (metode dingin) mempunyai banyak keunggulan dari sisi produk yang dihasilkan yaitu mempunyai kandungan antioksidan yang lebih besar sehingga metode ini menjadi pilihan untuk menghasilkan $V C O$ yang berkualitas. Metode dingin dalam pembuatan $V C O$ dapat dilakukan dengan beberapa cara yaitu dengan metode pemancingan, metode titik isoelektrik, metode peragian atau fermentasi dan metode enzimatis(Setiaji dan Prayugo, 2006; Ishak dkk., 2016; Muharun dan Apriyantono, 2014; Rahmawati dan Khaerunisya, 2018; Rindawati, 2020).

Metode pembuatan $V C O$ dengan metode enzimatis dan fermentasi merupakan salah satu metode pembuatan VCO tanpa pemanasan yang sederhana sehingga dapat di praktekkan dengan mudah oleh ibu-ibu rumah tangga sasaran dari kegiatan ini. Permasalahannya adalah metode ini belum banyak dikenal oleh masyarakat umum, khususnya masyarakat Kelurahan Pematang Gubernur RT 12 RW 03, Kecamatan Muara Bangkahulu, Kota Bengkulu. Oleh karena itu pelatihan pembuatan virgin coconut oil (VCO) dengan metode enzimatis dan fermentasi ini perlu dilakukan. Adapun manfaat yang diharapkan dari kegiatan PPM ini adalah untuk meningkatkan kesehatan dan perekonomian masyarakat di RT 12 RW 03 Kelurahan Pematang Gubernur, Kecamatan Muara Bangkahulu, Kota Bengkulu dalam suasana yang masih diliputi pandemi covid 19 saat ini.

\section{METODE PELAKSANAAN}

Kegiatan Pelatihan Pembuatan Virgin Coconut Oil (VCO) Dengan Metode Enzimatis Dan Fermentasi ini dimulai dengan ceramah untuk menjelaskan kepada ibu-ibu warga RT 12 RW 03 kelurahan Pematang Gubernur, Kecamatan Muara Bangkahulu mengenai VCO dan manfaatnya bagi kesehatan serta bagaimana cara membuat VCO agar diperoleh kualitas yang baik. Secara skematis urutan Pembuatan Virgin Coconut Oil (VCO) Dengan Metode Enzimatis dan Fermentasi ditampilkan pada Gambar 1.

Selanjutnya dilakukan diskusi untuk memberi kesempatan kepada ibu-ibu rumah tangga peserta kegiatan ini untuk menanyakan yang belum jelas mengenai $V C O$ dan cara pembuatannya yang akan dilakukan dalam kegiatan ini. Langkah selanjutnya adalah praktek untuk mempraktekkan metode pembuatan $V C O$ dengan metode enzimatis dengan ekstrak buah nanas dan fermentasi dengan ragi roti bersama-sama dengan ibu-ibu rumah tangga sasaran kegiatan ini. Metode ini dilakukan dengan melibatkan semua ibu-ibu rumah tangga peserta kegiatan ini. Metode ini dimulai dengan pemarutan kelapa, pembuatan santan kanil (krim santan), pembuatan ekstrak buah nanas dan kemudian pembuatan $V C O$ dengan metode enzimatis dengan ekstrak buah nanas dan fermentasi dengan ragi roti untuk mendapatkan $V C O$ dengan kualitas yang baik

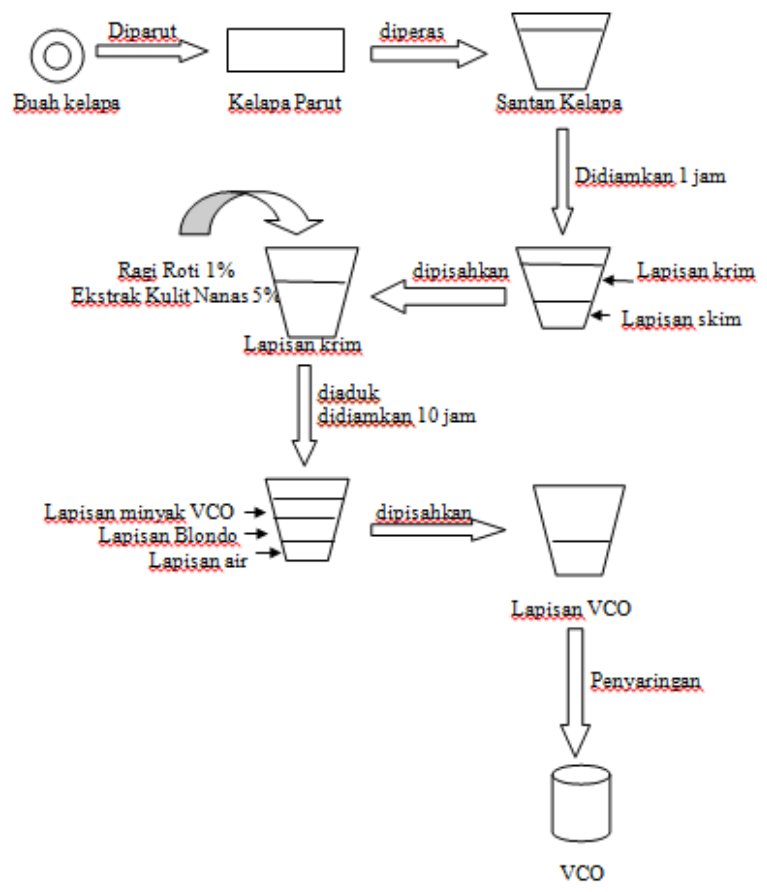

Gambar 1. Tahapan pembuatan $V C O$

\section{HASIL DAN PEMBAHASAN}

Berdasarkan pengamatan yang dilakukan sesudah pelaksanaan kegiatan pengabdian pada masyarakat ini terlihat bahwa masyarakat khususnya ibu-ibu masyarakat khususnya ibu-ibu rumah tangga di RT 12 RW 03 Kelurahan Pematang Gubernur, Kecamatan Muara Bangkahulu, Kota Bengkulu terlihat sangat antusias mengikuti seluruh kegiatan ini mulai dari penjelasan hingga praktek pembuatan VCO dengan metode enzimatis dan fermentasi. Antusiasme masyarakat ini terlihat dari jumlah ibu-ibu peserta yang hadir pada kegiatan ini yaitu seebanyak 30 orang. Antusiasme masyarakat ini juga ditunjukkan dengan banyaknya pertanyaan pada sesi diskusi yang berkaitan dengan pembuatan VCO dan pemanfaatannya untuk kesehatan. Keadaan ini disebabkan karena masyarakat khususnya ibu-ibu warga RT 12 RW 03 Kelurahan Pematang Gubernur, Kecamatan Muara Bangkahulu, Kota Bengkulu merasa mendapatkan tambahan pengetahuan baru yang sangat bermanfaat yang langsung bisa diparaktekkan dengan menggunakan bahanbahan yang sudah dikenal dan dapat diperoleh dengan 
mudah dilingkungan sekitarnya, yaitu teknologi sederhana pembuatan $V C O$ dengan salah satu metode tanpa pemanasan yaitu metode enzimatis dan fermentasi yang berbeda dengan metode yang sudah dikenal selama ini. Pengetahuan tersebut dapat melengkapi pengetahuan mengenai teknik pembuatan minyak kelapa yang biasa dilakukan masyarakat yaitu dengan pemanasan, sehingga dapat dijadikan sebagai alternatif teknologi pembuatan minyak kelapa yang sangat baik untuk kesehatan masyarakat. Gambar 2 adalah beberapa dokumentasi kegiatan pengabdian pada masyarakat ini.
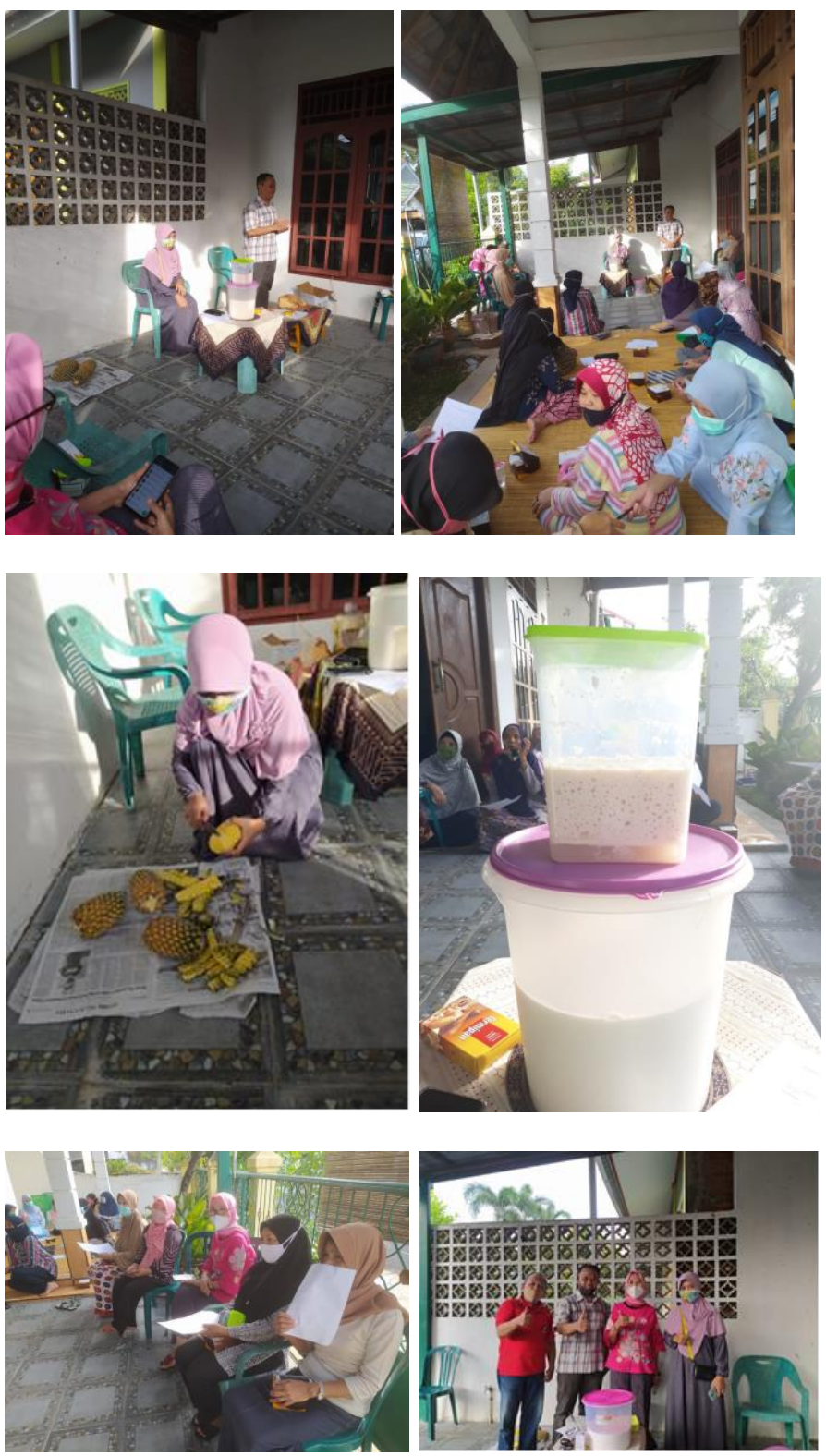

Gambar 2. Foto-foto prosesi sosialiasi pembuatan $V C O$

Gambar 2 tersebut menunjukkan masyarakat sasaran terlihat sangat antusias dalam mengikuti pelatihan pembuatan $V C O$ dengan metode tanpa pemanasan yang diberikan tim sehingga sesudah mengikuti pelatihan yang diberikan pada kegiatan ini ibu-ibu dan remaja putri warga RT 12 RW 03 Kelurahan Pematang Gubernur, Kecamatan Muara Bangkahulu, Kota Bengkulu, sangat antusias untuk dapat membuat sendiri $V C O$ dengan metode yang disampaikan dengan menggunakan peralatan sederhana yang sudah tersedia di rumah masing-masing. Hal ini disebabkan karena alat dibutuhkan untuk membuat VCO dengan metode ini menggunakan teknologi yang sangat sederhana dan mudah dimengerti oleh masyarakat. Disamping itu berdasarkan penjelasan yang diberikan, alatalat yang dibutuhkan tersebut semuanya sudah tersedia di rumah yaitu berupa toples, saringan kelapa, corong dan selang.

Bahan yang digunakan juga dapat diberoleh dengan sangat mudah di pasar karena biasa digunakan untuk keperluan sehari-hari. Selanjutnya, dari percobaan pembuatan VCO yang dilakukan ternyata setiap liter santan kelapa yang digunakan diperoleh $V C O$ sebanyak $+300 \mathrm{ml}$. Selain itu, minyak $V C O$ yang dihasilkan hampir tidak berwarna atau jernih. Hal ini tentu saja sangat menguntungkan karena dalam pembuatan ini akan diperoleh $V C O$ yang mempunyai nilai jual tinggi (Rp. 30.000,- setiap $100 \mathrm{ml}$ ) dan dapat digunakan untuk pengobatan berbagai penyakit, sehingga secara ekonomis sangat menguntungkan masyarakat (Setiaji, 2013).

\section{KESIMPULAN}

Berdasarkan hasil pelaksanaan kegiatan pengabdian pada masyarakat ini, maka dapat dibuat kesimpulan sebagai berikut:

1. Setelah dilakukan kegiatan PPM mandiri, maka masyarakat, khususnya ibu-ibu warga RT 12 RW 03 Kelurahan Pematang Gubernur, Kecamatan Muara Bangkahulu, Kota Bengkulu mengetahui berbagai manfaat yang sangat baik dari $V C O$ bagi kesehatan.

2. Masyarakat khususnya ibu-ibu warga RT 12 RW 03 Kelurahan Pematang Gubernur, Kecamatan Muara Bangkahulu, Kota Bengkulu dapat membuat sendiri VCO dengan cara selain yang sudah dikenal selama ini.

3. Dengan membuat sendiri $V C O$ maka masyarakat khususnya ibu-ibu warga RT 12 RW 03 Kelurahan Pematang Gubernur, Kecamatan Muara Bangkahulu, Kota Bengkulu akan dapat meningkatkan kesehatan keluarganya disamping meningkatkan penghasilan keluarganya yang akhirnya akan dapat meningkatkan kesehatan masyarakat. 


\section{UCAPAN TERIMAKASIH}

Penulis mengucapkan terima kasih kepada Jurusan Kimia dan Fakultas MIPA Universitas Bengkulu yang berkenan membiayai kegiatan Pengabdian Pada Masyarakat ini dengan dana RBA S2 Kimia Tahun 2020 dengan nomor kontrak : 3571/UN30.12/HK/2020

\section{DAFTAR PUSTAKA}

Hegde, B.M., 2016, Coconut Oil - Ideal Fat next only to Mother's Milk, Journal, Indian Academy of Clinical Medicine, Vol. 7, No. 1

Ishak, Aji, A. dan Israwati, 2016, Pengaruh Waktu Fermentasi Dan Berat Bonggol Nanas Pada Pembuatan Virgin Coconut Oil (VCO), Jurnal Teknologi Kimia Unimal, Vol. 5, No. 1, 66-77

Muharun dan Apriyantono, M., 2014, Pengolahan Minyak Kelapa Murni (VCO) dengan Metode Fermentasi Mmenggunakan Ragi Tape merk NKL, Jurnal Teknologi Pertanian, Vol. 3, No. 2

Prior, I.A., F.R. C.P., F.R.A. C.P., Davidson, F., Salmond, C.E. and Czochanska, Z., 1981, Cholesterol, coconuts, and diet on Polynesian atolls: a natural experiment: the Pukapuka and Tokelau Island studies, The American Journal of Clinical Nutrition, 34: pp. 1552-1561.

Rahmawati, E. dan Khaerunisya, N., 2018, Pembuatan VCO (Virgin Coconut Oil) dengan Proses Fermentasi dan Enzimatis, Journal of Food and Culinary, Vol. 1, No. 1, 16

Rindawati, 2020, Studi Perbandingan Pembuatan Vco (Virgin Coconut Oil) Sistem Enzimatis Dan Pancingan Terhadap Karakteristik Minyak Kelapa Murni Yang Dihasilkan, Indonesian Journal of Laboratory, Vol. 2, No. 2.

Setiaji, B. dan Prayugo, S., 2006, Membuat VCO Berkualitas Tinggi, Penebar Swadaya, Jakarta

Setiaji, B., 2013, Coco Power, Model Pemberdayaan Masyarakat Petani Kelapa, Coco Power Press, Yogyakarta 